\title{
ENABLING AGENCY THROUGH PARTICIPATORY ACTION RESEARCH IN AN HONOURS-LEVEL POSTGRADUATE CLASS IN A SCHOOL OF EDUCATION
}

\author{
A. Pillay \\ School of Education: Edgewood Campus \\ University of KwaZulu-Natal \\ Durban, South Africa \\ e-mail: Pillaya3@ukzn.ac.za
}

\section{ABSTRACT}

This article argues that it is feasible to use participatory action research to enable agency in a university lecture room. Underpinned by critical pedagogy, this qualitative study, shaped by a critical paradigm, used three cycles of planning, acting, observing and reflecting with 14 honourslevel postgraduate students. After each cycle, data generating methods, including written opinion pieces, open-ended questionnaires, and short written tasks, were used to ascertain the effectiveness of various interventions in facilitating the teachers' understanding and/or enactment of agency. Findings included, firstly, that explicit teaching about the concept "agency" is required for full understanding of the concept. Secondly, while participants engaged with the complexities of agency, they displayed increasing independence of thought and confidence in written and oral work. Finally, they understood the need for life-long learning and regular reflection on their professional identities.

Keywords: agency, critical pedagogy, explicit teaching, lifelong learning, participatory action research, reflection

\section{INTRODUCTORY COMMENTS}

Teachers, both at schools and at higher education institutions, work in diverse contexts and with various resources. This article contends that if teachers, despite contexts, are not made aware of their ability to determine their teacher identity, teaching practices, and possible outcomes, they may not be able to identify the powers that influenced and still influence them. They may thus replicate a prevailing system that might not be empowering or successful, and students will be forced to endure the effects of such a system.

Many South African classrooms, despite over 20 years of democracy, are still characterised by a history of repression. Among many possible solutions is the focus on the teacher who could be empowered to face the challenges within the South African context, teach to right the wrongs, and make a difference to the lives of students. In other words, teachers could make a difference if they had agency. 
There are many ways to conceptualise agency, but this article uses agency to refer to people's capacity to "critically shape their responses to problematic situations" (Biesta and Tedder 2006, 143). People may realise agency differently in different times and spaces (Archer 2000) and the possibilities for agency are fluid and changeable, and are dependent on the conditions, encounters and events in their lives (Archer 2000).

In this article, I reflect on how I used participatory action research in a university lectureroom in a School of Education in KwaZulu-Natal, South Africa to enable teachers to interrogate their agency. This study worked with 14 language teachers pursuing honours-level postgraduate studies. It was based on the contention that if teachers are empowered with understandings of how to understand and enact their agency, they may be able to empower their students similarly. This article argues that it is feasible to use participatory action research to enable agency in a university lecture room. The study aimed to respond to the question: In what ways may the activities in a lecture-room enable teachers to interrogate their agency in their classrooms?

The study worked with teachers doing the Critical Awareness of Language and Media honours-level module within a Language and Media Studies postgraduate programme. The module aims to develop an awareness of the role that language and media play in our contemporary lives and the correspondingly critical task of education, and to introduce educators to recent theoretical developments to inform practical engagement in the field of language and media education. By the end of the module, students should be able to, among others, define and locate language and media education within a critical educational paradigm.

I had taught this module previously and realised that I needed to change and improve the practices of meditating this module and in the process, improve myself. I believed that there was great potential for this module to use participatory action research to enable teachers to reimagine education and educational research generally and to interrogate their agency in their classrooms, more specifically.

In order to discuss this study, I have structured the article by considering the following:

- The theoretical underpinning of the study.

- A literature review of some relevant studies.

- A brief outline of the participatory action research process used.

- $\quad$ Discussion of findings.

- Concluding Thoughts. 


\section{THE THEORETICAL UNDERPINNING OF THE STUDY}

The study was underpinned by critical pedagogy, and draws on the four types of agency as conceptualised by Campbell, Schwier and Kenny (2009). Critical pedagogy, which is premised on conceptions of transformation towards social equality (Biesta and Tedder 2007; Giroux 2009), recognises a significant role for education. It is motivated by Dewey's contention that education can either serve to produce submissive citizens adhering to the status quo or function to create citizens who inform themselves in order to strive for justice and equality (Giroux 2009). Freire (1970) asserted that teachers and students should be agents who actively and collectively engage in the activity of creating meanings within the educational context. He recognised the role that critical pedagogy can play to underscore issues of democratic participation, agency, and voice (Darder, Baltodano and Torres 2009). This study's main concern was to interrogate and enable agency in a lecture room, and it used both active democratic participation and participants' voices to do so. Critical pedagogy, as a theoretical framework thus proved suitable to underpin the study. Critical pedagogy advocates for all participants in an educational setting to be empowered to understand their potential for agency to confront beliefs and practices that emphasise the permanence of the past. Its emphasis on human agency and on the potential for change (Giroux 2009; Darder et al. 2009) synchronised with the key constructs within this study.

In order to consider a concept such as agency, critical pedagogy calls for dialectical thinking (Giroux 2009) which fosters a "questioning form of thinking" and "reflections back and forth" (Carr and Kemmis 1983, 36-37). Dialogue and conscientisation, are encouraged in order to raise participants' critical social consciousness. Dialogue and questioning require reflection and action, and support a problem-posing approach in the educational setting (Freire 1970).

Since the study considers how the activities in a lecture room may enable teachers to interrogate their agency in their classrooms, I needed to enhance the use of critical pedagogy with a conceptualization of agency. I thus worked with the identification of four types of agency as conceptualised by Campbell et al. (2009). Firstly, interpersonal agency highlights shared commitments, activism, ethical obligations, and responsibility. In an academic setting, the teacher would implement changes on behalf of students, who might not understand the possibilities of using their voice. The teacher advocates for them until they can do so themselves. Interpersonal agency works in a setting of shared confidences and respect as students work collaboratively and with respect. I trusted that the teachers in this study would realise interpersonal agency as the study progressed.

Professional agency is the second type of agency. Here, an individual is bound by the 
principles of the profession. In a school or tertiary institution, such principles could include effective teaching and learning, enabling the transformation of students, and demonstrating fair and principled behaviour. These, and other principles, were foregrounded within this study.

Institutional agency, the third type of agency, recognises where the power to change is located and how the change is navigated. If conditions are optimal, a person should be able to find affiliation with the culture and philosophy of an organisation. However, should there be dissonance in the values of a person and the organisation, agency on the part of the person is compromised. When organisations challenge and fight change, agency is compromised.

The fourth type of agency is societal agency. This type of agency ensues when a person understands how change may move beyond the proximate surrounding to provide towards the greater community. In a school or tertiary institution, this type of agency goes beyond the subject matter to recognise students' backgrounds, needs, threats, and areas of location, and to be able to identify and work with high-risk students. This type of agency is often arduous.

\section{A LITERATURE REVIEW OF SOME RELEVANT STUDIES}

In this study, I draw on literature focussing on teachers' agency. McLaren (2000) suggests that the starting point to any study dealing with teachers' agency is to enable teachers to become critically self-reflective by considering the factors that have shaped their ideologies. School classrooms reflect both teachers' and students' ideologies and while many teachers recognise the complexities of, sometimes competing, ideologies, they do not or cannot address them. They also believe that they do not possess the skills to address students' intolerances and discriminations (Hollins and Guzman 2005). Similarly, teachers believe they do not have the skills to assist their students to deverlop into truly critical, creative and curious thinkers (Lemann 1999). Yet, hooks (1994) asserts that classrooms are ideal environments where students and teachers may reflect, think creatively and critically, and generate novel ways of thinking. hooks' assertion that classrooms, notwithstanding their difficulties, may serve as environments of reflection, innovation and inspired ideas, provided food for thought to the participants as they started the study. Recognising how teachers in other contexts interrogate agency despite challenges, helped participants in this study to contextualize their circumstances.

In Pakistan, Ali (2011) found that teachers understood and embraced agency in their roles in the classroom, the school and the community. In rural India, Contractor (2004) worked with female teachers and found that teachers with agency served as role models to the community, and students seemed eager to complete their education. In Tunisia, Kennedy (1987) set up a study with teachers that aimed for agency by focussing on the development of teachers and on the design of teaching materials. The study found that the use of collective decision-making 
during the development of materials, enabled teachers to have ownership of the process and products created. It was found that it is essential to embrace the experiences of the participants and the theories to which they subscribe, if aims of change agency are to be achieved.

In Canada, Fullan $(1993 ; 2001)$ noted that teachers with agency create strategies to realise the objectives that guide the progress of their students. These strategies are supported by four requisites: personal vision building, inquiry, mastery, and collaboration. While Fullan (1993, 12) stressed that content knowledge and pedagogical skills were of great importance, he noted that "the teacher of the future must actively improve the conditions for learning in his or her immediate learning environments". Fullan also urged teachers to equip learners to utilise their skills to act in response to situations beyond the classroom.

The studies above highlight the idea that teachers will function as agents of change when they appreciate the significance that accompanies the position, accept it willingly, and assume ownership of their choices. In addition, teachers as agents of change contemplate and question their practices and choice of guiding theories (Kennedy 1987). They also depend on themselves, not on outside forces, to transform their students' lives (Contractor 2004; Ali 2011). They are dynamic, involved teachers (Ali 2011) who function as role-models to both their students and the community, and they are determined to enhance the surroundings within and beyond the school (Fullan 1993; 2001; Contractor 2004; Ali 2011). It is clear, from the studies cited, that teacher agency feasible and it is thus important to enable and interrogate such agency in teachers.

\section{A BRIEF OUTLINE OF THE PARTICIPATORY ACTION RESEARCH PROCESS USED}

Working off a critical paradigm and a participatory action research design, the study worked with 3 cycles of planning, acting, observing and reflecting with a group of 14 Honours students. Participatory action research (PAR), a form of action research, is a qualitative research design that aims to bring about social change (McNiff and Whitehead 2006). Like action research, PAR involves a cyclic process of research, reflection, and action. It is considered an alternate design to established social or scientific designs, as it is underpinned by a participatory framework that is embedded within participants' social contexts. Thus, the research is a shared enterprise shaped by numerous influences within and outside the research space.

The roots of PAR may be traced to Paulo Freire, who recognised the potential of PAR for intervention, development and change within groups. Freire (1970) held that critical reflection was essential for personal and social transformation. As this study required participants to interrogate their agency, critical reflection was imperative for personal and social 
transformation, and PAR proved suitable to enable such reflective processes.

In keeping with requirements for PAR, the first step in this study entailed collecting baseline information. Baseline information allowed the participants and me to understand how the group perceived and experienced the concept, agency. Baseline information informed me how to choose relevant interventions to take the study forward. Baseline information was generated from an anonymous free writing task on the concept "agency". Once written, I taught the participants how to analyse qualitatively, focussing on looking for themes and patterns and then coding the data, and written tasks were randomly given to the participants who analysed the data in pairs. Thereafter, I analysed each written task, thus enabling a second round of analysis. The free writing task not only taught participants how to analyse data but also exposed them to ideas, other than their own, about agency. This process of analysis was used throughout the study. In the main, the process of analysis was ongoing and iterative in generating and analysing data (Johnson and Christensen 2007) and this started after the baseline information was generated.

Once the baseline information was analysed, I determined out what the interventions ought to be. Cummings and Worley (2005) note that interventions are a collection of prepared actions devised to heighten the efficacy of a situation, and intentionally disrupt existing practices. Sound interventions need to be responsive to the needs of a situation, established on causal information of planned outcomes, and devised so that the implementation of the intervention may be conveyed to the participants (Argyris, Putnam and Smith 1985).

Every cycle of the participatory action research included an intervention aimed to ascertain the extent to which the teachers were grappling with and enacting agency in the lecture room and beyond. The interventions functioned within the participatory action research spiral of cycles and at each four-week cycle, the intervention was implemented, observed, reflected on and theorised in advance of additional action. Following each cycle, various research methods were employed to generate data on the success of the interventions in enabling the teachers' knowledge and/or enactment of agency. The three cycles worked as follows:

Cycle 1: Critical Pedagogy served as the springboard to interrogate issues surrounding agency. Explicit teaching, readings and discussion served as the interventions in this cycle. After the cycle, an open-ended questionnaire was administered and findings were analysed by the participants and then by me. Collective reflections and decisions on the way forward followed.

Cycle 2: Critical Thinking, Critical Language Awareness and Critical Literacy served as the topics that enabled engagement with issues surrounding agency in the language classroom. Role-plays functioned as the interventions. After the cycle, opinion pieces were written, and 
findings were analysed by the participants and then by me. As for cycle one, reflections and joint decision-making ensued.

Cycle 3: Semiotics, Genre Theory, Narrative Theory, Representation, Discourse Analysis and Critical Discourse Analysis were used critically to analyse texts, interrogate ways of being in the classroom and beyond, and to consider how teachers could serve as agents of change. Problem posing prompts were used as the interventions. After the cycle, participants presented a piece, in the form of a debate or seminar, on "agents of change in the language classroom", and findings were analysed by the participants and then by me. Final reflections by all participants ended the study.

Of the participants, there were nine females and five males, and 13 students were South African and one student was Nigerian. Their ages ranged from eight participants in their 20s, five in their 30s, and one who was in her 40s. Eleven teachers taught at high schools; two taught at primary schools; and one taught at a tertiary institution. Racially, the university records indicate that there were 11 Africans, two Indians and one Coloured in the group.

While the profiles of the participants are important, PAR recognises that the stance of the researcher needs to be transparent. In the study, while I needed to be conversant with PAR and with the qualitative research methods used, I also needed ongoing reflection on my core values, experiences and ideas of agency, understanding that I entered the research space with the privileges and power, both personal and institutional, that come with being their lecturer and assessor (Brydon-Miller 2008). I also needed to be cognisant of the fact that it was imperative to enable all participants to participate, influence, and monitor the research processes and choices. Thus, the PAR aims and methods needed to be transparent to all participants, contributing to the validity of the research.

To enable trustworthiness, I understood the need not to be manipulative and controlling of the data generation and analyses processes, but to be open to emerging data while maintaining an empathic, non-judgemental stance. I needed to be respectful of and responsive to participants' responses while being mindful of the dynamics playing out with the research space (Johnson and Christensen 2007). Using an iterative process, the participants had to reflect on data generated previously while reflecting on their own voices and agency. In line with PAR, the spiral of cycles enabled the data generation and analysis to overlap, and ensuing cycles were informed by the evaluation and analysis of data from preceding cycles.

During the analysis, participants functioned as co-analysers, overseers and corroborators of the research process. Low inference descriptors were used, expressed very closely to the participants' words, and verbatim evidence assisted in confirming findings (Johnson and Christensen 2007). While collective reflections occurred after each cycle, I also needed to 
reflect individually in order to theorise what the findings revealed, including the study's limitations.

I needed to handle two overt limitations to the methodology. The first limitation was the ad hoc nature of PAR where interventions could only be planned once the previous cycle was reflected upon. To counteract this limitation, all participants reflected upon the cycles, designed and effected new cycles, and theorised all findings. The second limitation involved me, as the researcher who was also the participants' lecturer and assessor. This concern was shared with the participants and I endeavoured to be alert to the power dynamics in the lecture room.

\section{DISCUSSION OF FINDINGS}

I discuss the findings by considering the generation of the baseline information and the three four-week cycles within which the study worked.

\section{Finding the point of departure: Baseline findings}

In the free writing task on "agency", prior to any intervention on the topic, twelve participants chose to write narratives, while one wrote a poem and another created a mind-map. The baseline findings were divided into 3 categories: The first category included participants who had some idea of the concept and who described "agency" with words such as "power", "action", "thinking for myself", "initiative", "catalyst", "potential" and "free choices", indicating a measure of responsibility and commitment to change, in line with Campbell et al.'s (2009) first type of agency, interpersonal agency. In his/her poem, a participant compared "load shedding" to a lack of agency, and "lights back on" to indicate agency, pointing to an awareness of the positive nature of agency. A participant identified his/ her parents and Nelson Mandela as people who demonstrated agency in their words and actions. However, s/he added that both the parents and Mandela displayed personality traits of "humility", "selflessness" and "openmindedness" and those traits enabled their agency. The participant could recognise societal agency in the examples cited, as espoused by Campbell et al. (2009).

The second category included participants who wanted to have agency but who were aware of possible limitations. A participant noted that $\mathrm{s} / \mathrm{he}$ wanted to be "an advocate for change", but was "doubtful at times," because "some problems are unsolvable". Another participant believed s/he had no agency in dealing with the school principal who "abused his power" and another noted that his/her agency in a classroom was demonstrated by the ability to "use my power to influence my students" but recognised the "potential for abuse" in this situation. Campbell et al. (2009) recognise the challenge to agency when a clash within an institution could disempower agency in a person. 
The third category included participants who understood their power but submitted to a higher power for agency. One participant indicated that s/he allowed the "power of prayer" to shape how s/he worked, and another noted, that "agency is determined by God's authority", indicating that they played no part in critically shaping their responses to situations (Biesta and Tedder 2006). Seven participants conceptualised agency as using "innovative teaching methods", possibly conflating innovation with agency. After considering the baseline findings, participatory action research cycle one began.

\section{Needing to make it clear}

In cycle one, carried out over four weeks, there was explicit teaching about critical pedagogy and resultant issues surrounding the concepts of agency, voice and democratic participation. Using explicit teaching, class discussions and various readings as interventions, participants recognised the role that agency could play in a teaching and learning situation. The findings from an open-ended questionnaire, administered after cycle one, showed that all participants credited the lecture sessions with making them think about themselves as potentially having agency in the classroom. Participants wrote, "I know I can make a difference", "I believe in my abilities to make a change" and "It's my classroom so I should take charge". The participants' words reflected a growing understanding of their potential to enact agency. They were beginning to build their personal visions, as espoused by Fullan (1993; 2001) and were demonstrating a move towards interpersonal agency in their espousal of moral responsibility and commitment (Campbell et al. 2009).

Two participants referred to finding their voices in "I didn't realise why I need to learn to speak up" and "My voice is as important as theirs". It was evident that the two participants understood the power of having a voice and that their voices and opinions mattered. Freire (1970), while advocating for teachers to have voice, recognises that critical pedagogy is an important means to engage with such issues. The findings indicated that the explicit teaching about using critical pedagogy in a classroom in order to have agency and voice might have inspired participants to see themselves as having both agency and voice.

Participants, in their open-ended questionnaire, noted, that "I learned something that I might never have thought about", "the discussions really pushed me to look at myself again" and "some readings were very hard but they were so relevant". It was evident that the explicit teaching was necessary to engage with the concepts in order to start the journey towards a sense of empowerment, in line with the tenets of critical pedagogy (Giroux 2009).

However, my making concepts surrounding agency clear and participants' thinking and writing about agency, while an important first step, does not necessarily represent participants' 
actual enactment of an interrogation and/or enactment of agency. During the reflections after cycle one participants made it clear that there was a need to locate the concept of agency in the language classrooms where they worked.

\section{Displaying increasing independence and confidence}

By cycle two, besides engaging with participants' understanding of enacting agency in the language classroom, there was also a need to interrogate their emerging identities within the research process. In cycle two, in addition to readings and discussion, we made extensive use of role-plays as interventions when discussing critical thinking, critical language awareness, and critical literacy. The repeated use of role-playing enabled an increased confidence in their oral work and this sense of confidence allowed participants to express themselves sincerely without needing necessarily to fit in with the sentiments of the group. Increasing independence of thought and confidence in expression was evident in their engagement with issues surrounding racism, sexism, sexuality, corporal punishment, and language teacher identity were reflected in their role-plays, and needed careful unpacking within the tenets of critical pedagogy.

Throughout the study, participants produced written pieces of varying lengths and for varying purposes. By cycle two, the independence of thought reflected in their work had progressed significantly and there was a reduction in unnecessary tentativeness and apologetic writing in many participants' written responses, especially those requiring a personal response such as the opinion piece.

At the end of cycle two, participants wrote an opinion piece on the topic, "Critical pedagogy may work to enable agency but not in South African language classrooms". Opinion pieces revealed that participants recognised the value of using critical pedagogy to enable agency in South African language classrooms and noted, "Critical pedagogy has opened my eyes to such potential", "the principles talk directly to the realities of a typical South African classroom", "I thought I taught critical thinking and critical literacy but I was wrong", and "agency in the classroom can work by using the ideas from critical pedagogy".

However, they could also identify and understand the complexities of agency. Participants noted, "I find myself constantly questioning everything that is said to me or everything that I read, even in my classroom", "my academic writing needs to be informed by the works of others so I find myself questioning my ability to think for myself", and "I want to be an agent of my future, an agent of change in my classroom, instead of letting my circumstances decide for me". These sentiments indicate that while participants were increasingly reflecting back and forth on their thinking and were questioning their long-held views, they were equally acknowledging 
their vulnerabilities, and this may be recognised as a sign of growth towards professional confidence. Giroux (2009) notes, that such dialectical thinking is necessary for the development of agency. Campbell et al. (2009) note that professional agency is seen when persons indicate a commitment to the ideals of the profession, and these participants were reflecting a move to such a commitment.

While the sentiments above reflect positively on an increasing independence of thought and move towards confidence in their journeys towards agency, three participants acknowledged, "I struggle to make choices and sometimes find myself conforming to things I do not believe in", "I see how I have been dictated to all my life" and "a person can learn to unlearn the things that society has made normal". While reflecting the complexities and dynamics of agency, the words also reflected a reflective practice that was encouraging. The participants could identify their weaknesses and their oppressions, and that is a possible first step towards righting a wrong.

The reflections after cycle two revealed that participants had "a strong understanding of agency" and knowledge of "how it can work in my classroom". By this stage, I also recognised that the participants' interactions and words reflected a sense of trust and respect. While the participants corroborated this finding, they only did so after I drew their attention to it. By this cycle, there was an easy rapport among the participants, much laughter ensued, many in-jokes started emerging and they were able to engage with each other, not just as fellow teachers and participants, but also as human beings. They appeared to feel confident to build on each other's responses and to question each other on issues raised, of their own volition. A participant noted, "It feels safe to say things here. I guess this is what we need to create in our classrooms". I believe that the extensive engagement on the various issues and the use of role-plays assisted greatly in building rapport so that they could display increasing independence and confidence. In the final cycle, we decided to take the process further to ascertain how a language teacher may serve as an agent of change in the language classroom.

\section{Understanding the need for reflection and life-long learning}

In cycle three, we worked with Semiotics, Genre Theory, Narrative Theory, Representation, Discourse Analysis and Critical Discourse Analysis to analyse various types of texts, interrogate ways of being in the classroom and beyond, and to consider how teachers could serve as agents of change. Together with the analyses of texts, problem-posing prompts were used as interventions, in line with Freire's (1970) suggestion that using problem-posing dialogue in an active, participatory, and reflective manner might enable critical thinking.

Towards the end of the cycle, participants presented a piece, in the form of a group debate 
or group seminar, on the broad topic, "agents of change in the language classroom", and participants could decide what they foregrounded in their presentations and how they would incorporate aspects learned in the module into the presentations. Participants recorded their presentations using cellphones, and these presentations were analysed by the participants and then by me.

Debates and seminars reflected innovative, confident presentations. The findings from cycle three reflected that 12 of the 14 participants had made sense of the content knowledge of the module and understood each section of the module. Two participants, both of whom had also not completed many written tasks based on readings and class interactions, appeared unsure of the content. The debates and seminars took many forms, with some participants presenting in character in various settings and some presenting in traditional formats. Some participants chose to use television debate and quiz show formats, and some presented their seminars as comedy and some as drama. This was despite not being given any instructions regarding the format. What most presentations revealed was an understanding of the work covered but they also revealed both a sense of creativity and a sense of agency in taking ownership of their presentations. They were also confident enough to open themselves up to scrutiny and even laughter.

The presentations revealed that participants understood how to start empowering themselves and their students. Comments such as "It is respect first in a classroom. If you don't respect your students, you cannot get through to them", "ensure that everyone gets a chance to participate", "let them talk, express themselves. That means you need to stop doing all the talking", and "start the dialogue" revealed an understanding of the dynamics of changing the classroom ethos. These ideas are in line with interpersonal agency (Campbell et al. 2009) which foregrounds giving students a voice, building relationships of trust and respecting all views.

Others pointed to the need to read and learn, with comments such as "every teacher must keep up to date with what's happening in education around the world. Nothing stays static" and "a teacher by definition is a learner for life". These comments reveal their understandings of why it is imperative that a teacher is a life-long learner. Other comments such as "a silent class is not a good class", and "don't be afraid to let them challenge you" showed an awareness of how long-held views might need unsettling. Critical pedagogy encourages teachers to empower students to recognise their own agency and to enable them to challenge ideas and practices (Giroux 2009; Darder et al. 2009). Many participants understood the power of reflection and noted, "Give them opportunities to think", "make them sit and think", "make them curious so that they want to know" and "you need to sit and think too, everyday". Professional agency (Campbell et al. 2009) is being called for as teachers reflect on their words and actions to try to 
make a difference to their students' lives.

By the end of the study, the participants had a clear understanding of their potential for agency. They had started working out a well-defined understanding of their roles and functions, and revealed a commitment to enhancing their own and their students' lives. In addition, they recognised the necessity for life-long learning and regular reflection on their professional identities.

Some unanticipated findings reflected the participants' understandings of the study in very practical ways. At a lecture session one day, a group of students sat outside our lecture room talking loudly. Just as I made my way to ask the group to move away, a participant said that she would talk to them, which she did. We had spoken about issues of respect and dignity in our lectures and her confident, yet sensitive, handling of the boisterous group reflected these issues. Another example was when students asked if I could meet with them during their school holidays for extra work and took the initiative to find venues and set up times for the days we met. They asked for additional engagement to grapple with questions on which they had reflected. These unanticipated findings, together with the findings above, indicate to me the participants' growing sense of agency in their academic, and potentially, in their professional, lives as well.

\section{CONCLUDING THOUGHTS}

The study worked with three cycles within a PAR study. The significance of the study rests, in large part, to the use of constant dialogue and reflection to enable agency. Dialogue and questioning in various forms characterised the study and reflection facilitated understandings and changes in our ways of acting and being. Our constant contemplations and deliberations on actions, experiences and ideas gleaned from the interventions, our experiences and the readings allowed us to make changes to our practices, assisted us to understand our roles and functions as teachers, and helped us to recognise our professional strengths and shortcomings. We also recognised the importance of a teacher advocating for the active involvement and empowerment of students so that they attain agency and voice. Thus, we were able to affirm that using participatory action research in a university lecture room is feasible to enable and interrogate agency.

The findings of this study reflect what happened during those three PAR cycles and I cannot say, with confidence, that all participants will carry the ideas into their classrooms. However, they engaged actively with issues of critical pedagogy, including democratic participation, voice and agency, and now understand how these concepts may be implemented in their professional lives. They now decide if or how they take forward the many possibilities for change. 


\section{REFERENCES}

Ali, T. 2011. Understanding the evolving roles of improvement-oriented high school teachers in GilgitBaltistan. The Qualitative Report 16(6): 1616-1644.

Archer, M. 2000. Being human: The problem of agency. Cambridge: Cambridge University Press.

Argyris, C., R. Putnam and D. Smith. 1985. Action science: Concepts, methods and skills for research and intervention. San Francisco: Jossey-Bass.

Biesta, G. J. J. and M. Tedder. 2006. Agency and learning in the lifecourse: Towards an ecological perspective. Studies in the Education of Adults 39: 132-149.

Brydon-Miller, M. 2008. Ethics and action research: Deepening our commitment to principles of social justice and redefining systems of democratic practice. In Sage Handbook of action research, ed. P. Reason and H. Bradbury, 199-209. Thousand Oaks: Sage.

Campbell, K., R. A. Schwier and R. F. Kenny. 2009. The critical, relational practice of instructional design in higher education: An emerging model of change agency. Educational Technology Research and Development 57: 645-663.

Carr, W. and S. Kemmis. 1983. Becoming critical: Knowing through action research. Victoria: Deakin University Press.

Contractor, H. 2004. Women teachers become agents of change. Infochange: News and analysis on social justice and development issues in India. www.infochangeindia.org (Accessed 3 April 2009).

Cummings, T. G. and C. G. Worley. 2005. Organisational development and change. $8^{\text {th }}$ Edition. Ohio: Thomson.

Darder, A., M. P. Baltodano and R. D. Torres. (Eds.). 2009. The critical pedagogy reader. $2^{\text {nd }}$ Edition. New York: Routledge.

Freire, P. 1970. Pedagogy of the oppressed. New York: Seabury.

Fullan, M. G. 1993. Why teachers must become change agents. Educational Leadership 50(6): 12-17.

Fullan, M. G. 2001. The new meaning of educational change. Toronto: Irwin Publishing Ltd.

Giroux, H. A. 2009. Teacher education and democratic schooling. In The critical pedagogy reader, ed. A. Darder, M. P. Baltodano and R. D. Torres, 438-459. New York: Routledge.

Hollins, E. and M. Guzman. 2005. Research on preparing teachers for diverse populations. In Studying teacher education: The report of the AERA panel on research and teacher education, ed. M. Cochran-Smith and K. M. Zeichner, 477-548. New Jersey: The American Educational Research Association.

hooks, b. 1994. Teaching to transgress: Education as the practice of freedom. New York: Routledge.

Johnson, B. and L. Christensen. 2007. Educational research: Quantitative, qualitative, and mixed approaches. $3^{\text {rd }}$ Edition. Los Angeles: Sage.

Kennedy, C. 1987. Innovating for change: Teacher development and innovation. ELT Journal 41(3): $162-170$.

Lemann, N. 1999. The big test: The secret history of the American meritocracy. New York: Farrar, Straus and Giroux.

McLaren, P. 2000. Che Guevara, Paulo Freire, and the pedagogy of revolution. Lanham: Rowman and Littlefield.

McNiff, J. and J. Whitehead. 2006. All you need to know about action research. London: Sage. 